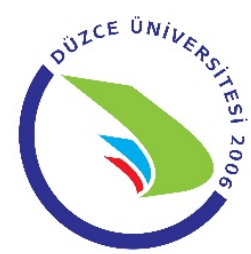

\title{
Bireylerin Ă̆ıZ ve Diş Sağlığına İlişkin Tutum ve Davranışlarının İstatistiksel Yöntemlerle İncelenmesi: Afyonkarahisar İli Örneği*
}

\author{
Fatma ATALAY [i] ${ }^{1}$, Sinan SARAÇLI [i] ${ }^{1}$
}

ÖZ

Amaç: $\mathrm{Bu}$ çalışmada, bireylerin ağız ve diş sağlı̆̆ konusundaki bilgiye ve korkuya dayalı tutum ve davranışlarının incelenerek, tutumlarının davranışları üzerindeki etkilerinin belirlenmesi amaçlanmıştır.

Gereç ve Yöntemler: Bu amaçla Afyonkarahisar il merkezinde faaliyet göstermekte olan özel diş kliniklerine, 2019 yılı Nisan-Mayıs aylarında tedavi amaçlı gelen toplam 350 hastaya uygulanan anket aracıllı̆ ile ilgili veriler toplanmıştır. Toplanan verilere, betimleyici istatistiksel analizlerin dışında açıklayıcı faktör analizi, doğrulayıcı faktör analizi ve yapısal eşitlik modellemesi uygulanarak bireylerin bilgiye ve korkuya dayalı tutum ve davranış boyutları belirlenerek ağız ve dış sağlığı konusundaki davranışları üzerinde etkili olan tutumları belirlenmiştir.

Bulgular: Açıklayıcı faktör analizi sonucunda bireylerin ağız ve diş sağlığı konusundaki tutumlarının alt boyutları: Korkuya dayalı Tutum (KT) ve Bilgiye dayalı Tutum (BT) olarak, davranışlarının alt boyutları ise Korkuya dayalı Davranış (KD), Bilgiye dayalı Davranış (BD) olarak belirlenmiștir. Faktör analizi bulgularına göre bireylerin korkuya dayalı tutumları üzerinde, en çok anestezik iğnenin görüntüsünün endişelendirdiği, Korkuya dayalı davranışları üzerinde en çok kullanılan aletlerin seslerinin rahatsız ettiği için müzik dinlemeleri etkili bulunmuş, Bilgiye dayalı tutumları üzerinde Ağız ve diş sağlığı genel vücut sağllğı ile etkileşim içinde olduğu, bilgiye bağl davranışları üzerinde ise Dişlerimi düzenli şekilde günde 2 defa firçalamaları etkili olarak bulunmuştur.

Sonuç: Yapısal eşitlik modellemesi sonucunda elde bulgulara göre, korkuya dayalı davranışları üzerinde korkuya dayalı tutumları en etkili faktör olarak belirlenirken, bilgiye dayalı davranışları üzerinde ise bilgiye dayalı tutumları en etkili faktör olarak belirlenmiştir.

Anahtar Kelimeler: Diş sağlığı taramaları; tutum; davranış; istatistiksel model.

\section{Analysis of the Attitudes and Behavior of Individuals on Oral and Dental Health by Statistical Methods: Sample of Afyonkarahisar Province}

\begin{abstract}
Aim: In this study, it was aimed to determine the effects of attitudes on behaviors of individuals by examining their attitudes and behaviors based on information and fear on oral and dental health.

Material and Methods: For this purpose, data was collected from a total of 350 patients who were treated for treatment in April-May 2019 in private dental clinics in Afyonkarahisar. In addition to the descriptive statistical analysis, descriptive factor analysis, confirmatory factor analysis and structural equation modeling were applied to the collected data. Attitudes and behaviors of individuals based on knowledge and fear were determined and their attitudes which had an effect on oral and dental health behaviors were determined.

Results: As the results of the explanatory factor analysis, sub factors of individuals' attitudes and behaviors towards oral and dental health is determined as fear-based attitudes (KT) and knowledge based attitudes (BT) and fear-based behaviors (KD) and knowledge based behaviors (BD). According to these findings, while fear of the view of anesthetic injection is the most effective on fear-based attitudes of the individuals, listening music because of the disturbance of the voices of the devices has the greatest effect on their fear-based behaviors. Besides, while Interaction between general health with oral and dental health is found effective on their knowledge based attitudes, brushing teeth twice a
\end{abstract}

1 Afyon Kocatepe Üniversitesi, Fen-Edebiyat Fakültesi, İstatistik Bölümü, Afyonkarahisar, Türkiye

*Bu çalışma Fatma ATALAY'ın Sinan SARAÇLI danışmanlığında, Afyon Kocatepe Üniversitesi Fen Bilimleri Enstitüsünde tamamladığı yüksek lisans tezinden üretilmiştir. 
day regularly is found effective on their knowledge based behaviors.

Conclusion: According to the results of the structural equation modeling, fear-based attitudes were determined as the most effective factor on the behaviors based on fear, whereas knowledge-based attitudes were determined as the most effective factor on knowledge-based behaviors.

Keywords: Dental health survey; attitude; behavior; statistical model.

\section{GIRIŞ}

Tüm dünyada ve ülkemizde de en sık görülen halk sağlığ sorunlarının başında ağız ve diş hastalıklarının yer aldığ 1 görülmektedir.

Bunun en önemli nedenleri olarak ulaşım olanakları, ekonomik problemler, farkındalık, eğitim ve dental korku gibi temel toplumsal problemler öne çıkmaktadır. 1992 yılında Sağlık Bakanlığı Sağlık Projesi Koordinatörlüğü tarafından yapılan araştırma sonucuna göre; gelişmiş ülkelerde nüfusun diş hekimine gitme sıklığı yılda 5 iken, ülkemizde bu oran 0,7'dir. Türk Diş Hekimler Birliği'nin resmi internet sitesindeki verilere göre; nüfusun \%47,11'inin son bir yılda, \%12,5'inin ise yaşam boyu hiç diş hekimine gitmediği tespit edilmiştir (1).

1992 yılında Sağlık Bakanlığı tarafından yapılan bu araştırma sonuçlarına bakıldığında ülkemizde ağız ve diş sağlığı problemlerinin gelişmiş ülkelere oranla daha yaygın olduğu görülür. Son yıllarda sağlık alanında yapılan harcamalar, toplumun bilinçlenmesi için yapılan koruyucu ağız ve diş sağlı̆̆ hizmetleri sayesinde Türk toplumu olarak iyi yönde bir ilerleme kaydedilmiştir.

Toplum olarak bilinçlendikçe birey bazında bilgi düzeyimizin arttığı ağız ve diş sağlığı hakkında bildiğimiz yanlış düşüncelerden kaynaklı korkuların da azaldığı görülmektedir. Bireyler bilgi, kanaat ve inançlarını ortaya çıkarmak istedikleri zaman bunu tutum ve davranışları ile belli etmeye çalışırlar.

$\mathrm{Bu}$ çalışmada, Afyonkarahisar il merkezinde faaliyet göstermekte olan özel ağız ve diş kliniklerine tedavi amaçlı gelen bireylerin ağız ve diş sağlığı konusundaki bilgiye ve korkuya dayalı tutum ve davranışlarını ölçmek için bir anket uygulanmıştır. Uygulanan anket sonucunda bireylerin ağız ve diş sağlığıyla ilgili tutumlarının davranışları üzerindeki etkilerinin belirlenmesi amaçlanmıştır.

\section{A ğız ve Diş Sağlığg}

Tüm dünyada ve ülkemizde de en sık görülen halk sağlığ sorunlarının başında ağız ve diş hastalıklarının yer aldığ görülmektedir (2).Ağız ve diş sağlığı tanımını açmak gerekirse; dişler, diş etleri ve onları destekleyen sert ve yumuşak doku (mukozal doku ve kemik doku), dil, dudak, tükürük bezleri, kaslar ve eklemler tarafindan iskelete tutunan tüm uzuvlarımızın sağlığını anlayabiliriz (3). Ağız kavitesi içerisinde bulunan bütün bu yapılar, insanların konuşma, tat alma, nefes alma, yeme ve içme gibi hayati fonksiyonlarını yerine getirebilmeyi sağlayan kısımdır. Ağı boşluğunun sağlığının bozulması insanların bu işlevleri yerine getirmesini engelleyebilir. Sonuç olarak, bireylerin günlük işlerini yapmalarını engelleyebilir. Aynı zamanda bireyin sosyal yaşamını da etkileyebilir ve kişilerarası iletişimde bozulmaya yol açabilmektedir $(4,5)$.
Genel sağlığın önemli bileşenleri, vücut için gerekli temel besin maddelerinin sağlanmasında kritik rol oynayan çiğneme ve yutkunma fonksiyonuna sahip olan ağız ve diş sağlığı açısından da önemlidir. Birçok ölümcül mikroorganizmayı barındıran ağız boşluğu, aynı zamanda çoğu iltihap için de giriş yeridir. Bu nedenle, genel sağlık için iyi bir oral hijyenin sağlanması gerekmektedir $(6,7)$. Ağız ve diş sağlığının bozulması hemen bir rahatsızlığa neden olmamaktadır, ancak uzun dönemde birçok sağlık problemine öncülük etmektedir. Ağız ve diş sağlığının bozulması ile beraber kardiyovasküler hastalıklar, enfeksiyöz hastalıklar, sindirim sistemi hastalıkları, solunum hastalıkları, kanser vb. birçok hastalıkta öncü risk faktörü olmaktadır (8).

Literatüre bakıldığında ağız ve diş sağlığının bozulmasındaki etiyolojik faktörlerden en önemlisinin dental plak olduğu görülmektedir (9). Ağız sağlığının bozulmasının en önemli nedenlerinden başında gelen dental plak birikiminin önüne geçilememesi sonucunda içerisinde bulunan organizmaların zararlı ürünler üretmesidir. $\mathrm{Bu}$ nedenle yapılan araştırmaların sonucuna bakıldığında plak birikiminin engellenmesinin ağız sağlığının kazanılması ve sürdürülmesi için zaruri olduğu anlaşılmaktadır $(10,11)$. Bireylerin bağlı olduğu toplum, yaşları, cinsiyetleri, beslenme alışkanlıkları, sistemik hastalıkları, kültürel ve sosyoekonomik durumları da ağız ve diş sağlıklarına gösterdikleri hassasiyet üzerinde önemli bir etkiye sahiptir (10,12-14).

\section{Bireylerde Ă̆ız ve Diş Sağlığı Bilgi Düzeyleri}

A ̆̆ız ve diş sağlığı profesyonellerinin sağlık durumunu ölçen birçok çalışma vardır. Bu çalışmalar temel olarak periodontal sağlığın genel sağlık üzerine etkileri ile ilgilidir. Ayrıca, bebeklerin ağız ve diş sağlığı, seyahat süresi ve florlu macun kullanımı bu tür çalışmalarla sinırlıdır $(8,15,16-18)$.

Sağlık bütünsel bir kavram olarak anlaşılmaktadır. Ağız ve diş sağlığ1, genel vücut sağlığıyla bir bütün şeklinde kabul edilir. Literatürde yapılan birçok çalışma ağız ve diş sağlığı koşullarının ve hastalıklarının evde, okulda, işte ve yaşamın tüm kesiminde insanları etkileyerek yaşam standartlarını etkilediği bulunmuştur $(1,19)$. Dünyada ve ülkemizde, diş hekimlerinin muayene ve tedavisinin ulaşım, ekonomik sorunlar, öncelik sırası ve farkındalık gibi nedenlerle sınırlı olduğu görülmektedir. Türk Diş Hekimleri Birliği'ne göre; geçen yıl nüfusun \% 47,11 olduğu ve hastaların \% 12,5'inin dişçiye gitmediği tespit edilmiştir (20). Bu durumda halk sağlığı yaklaşımı, erişkin ve çocuklarda ağız ve diş sağlığının korunması, daha iyi bir noktaya gelmesi gibi konularda önemli bir yer tutar (21). Ağız ve diş sağlığında meydana gelen problemler genel olarak bebeklikten başlayıp ihtiyarlık dönemine kadar devam eder. Dünya Sağlık Örgütü ülkelerinin ağız sağlığı seviyelerinin belirlenmesinde de çocukluk çağına göre incelendiğinde; 5, 12, 15 yaş gruplarının ağı ve diş sağlığı seviyelerinin belirlenmesinin yeterli olduğu görülmüş̧tür (22). Özellikle 11-12 yaş arası çocuklarda daimi dişlerin çıkmasıyla ağızdaki dişler tamamlanmaktadır. Bu nedenle, çocuklarda kalıcı diş çürüğünün tespiti ve koruyucu sağlık davranışının gelişimi için önemli bir süre olduğu görülebilir (23). Okul çağındaki çocuklarda görülen ağız ve diş sağlığı sorunlarının başında; yerleşim bozuklukları, diş eti hastalıkları, diş çürüğü, travma ve 
yaralanmalar olarak görülmektedir (24). Diş çürükleri genel olarak, çocuklarda en sık gözlenen kronik hastalıklardan biri olduğu belirtilmiştir $(21,25)$. Tekçiçek (21) yaptığı çalışmasında; diş çürüğünün saman nezlesinden yedi kat, astımdan beş kat daha sık görüldüğü belirlenmiştir. Diş çürümesi sebebiyle erken bir diş kaybı, okula devamsızlık, konuşma bozukluğu, büyüme geriliği ve okulda konsantrasyon kaybına neden olabilmektedir. Literatürdeki kaynaklara göre, öğrenciler diş problemleri sebebiyle yılda yaklaşık 51 milyon saat kaybediyorlar $(21,26,27)$. Ülkemizin nüfusunun büyük bir kısmını, okul çağı çocukları oluşturmaktadır (28). Çocuklarda, iyi ağız ve diş sağlığı için davranış değişikliklerine yol açabilecek uzun süreli ve düzenli sağlık eğitimi olmalıdır. Bu eğitim için en uygun yerler, çocuklara aynı koşullar altında ve aynı ortamda öğretilen okullardır (29). Güler ve ark. (30) yaptıkları bir çalışmada, okul ortamında ağız sağlığı ve diş sağlığı konusunda, tüm okul, aile ve sosyal çevre ile ilgili sorunları tespit etmek ve etkili ağız ve diş sağlığı eğitimi programları geliştirmek için eğitim sağlamakla ilgilenmektedirler. Olumlu diş sağlığı davranışlarının gelişimine katkıda bulunduğu tespit edilmiştir.

\section{Bireylerde Ağız ve Diş Sağlığı Korku Düzeyleri}

Korku ve anksiyete birbirlerini tetikleyerek meydana gelen ve bunun sonucunda da ağı ve diş sağlığ uygulamalarında hekime ve hastaya tedavinin işleyişinde önemli sorunlar oluşturan faktörlerdir. Korku, bireylerin başına gelen tehlikeli durumlarda oluşan hayatta kalma içgüdüsüne bağlı meydana gelen duygusal bir tepkidir (31). Korkuda tehlikenin kaynağı doğrudan mevcut iken anksiyetede böyle bir durum söz konusu değildir (32). Anksiyete ise tehdit sonucu meydana gelebilecek zararın çok az olarak tanımlandığı, görünmez olduğu hatta olmadığı, duygusal bir tecrübe olarak tanımlanır (31). Anksiyete, hastaların ifade etmede zorlandığı bir huzursuzluk, panik ve endişe hali olarak da tanımlanabilir (32). Anksiyete sonucunda diş hekimine gelen hastalarda birçok fiziksel ve davranışsal problemler(terleme, tansiyon düşmesi, titreme, baş dönmesi vb.) ortaya çıkmaktadır bunun sonucunda da hasta ve hekim için büyük bir problem oluşturmaktadır (33).

Dental enjektör, kesici ve delici aletlerin varlığ 1 , hekimin bireysel tutumu işlemlerin uzun sürmesi, anksiyete koşullarını meydana getiren faktörlerdir (34). Hastanın beklentileri, tedavi sürecinin kontrolünün dışında olması ve hastanın diş tedavilerinin işleyişi hakkında bilgi düzeyi stresi arttıran diğer faktörlerdendir (35).

\section{GEREÇ VE YÖNTEMLER \\ Evren ve Örneklem}

$\mathrm{Bu}$ çalışmada, Afyonkarahisar ilindeki bireylerin ağız ve diş sağlığı konusundaki bilgiye ve korkuya dayalı tutum ve davranışlarının incelenerek, tutumlarının davranışları üzerindeki etkilerinin belirlenmesi amaçlanmıştır. $\mathrm{Bu}$ amaçla hazırlanan bir anket formu aracılı̆̆ ile il merkezinde bulunan 7 poliklinik ile 16 Muayeneye gelen hastalar arasından rassal olarak seçilen bireylerden ilgili veriler toplanmıştır. İlgili anket formunda bireylerin demografik özelliklerinin yanında ağız ve diş sağlığına ilişkin tutum ve davranışlarını belirlemek amacıyla 5'li Likert tipinde (1. Hiç katılmıyorum, 5. Tamamen Katılıyorum) soruların yer aldığı ölçek kullanılmıştır. Ölçekte yer alan soruların bir kısmı alanında uzman diş hekimlerine danışılarak, araştırmacı tarafindan hazırlanmış olmakla birlikte, Ay ve ark. (36), Tezel ve Yaman (37), Pekiner (38) ve Yüksel (39)'in çalışmalarından derlenmiştir.

Hazırlanan anket formu 2019 yılı Nisan-Mayıs aylarında il merkezinde faaliyet göstermekte olan özel ağız ve diş sağlığı kliniklerine, tedavi amaçlı gelen toplam 358 hastaya uygulanarak ilgili veriler toplanmıştır. İl merkezindeki özel ağız ve diş sağlığı kliniklerinde görev yapmakta olan diş hekimleri ile yapılan görüşmeler sonucunda bu süreç içerisinde bu merkezlere gelebilecek toplam hasta sayısının en fazla 3000 kişi olabileceği göz önünde bulundurularak örneklem hacminin \%95 güvenirlilikle bu büyüklükteki bir anakütle için $\mathrm{n}=$ $\mathrm{N} * \mathrm{t} 2{ }^{*} \mathrm{p} * \mathrm{q} / \mathrm{d} *(\mathrm{~N}-1)+\mathrm{t} 2 * \mathrm{p} * \mathrm{q}$ formülü yardımı ile $(\mathrm{p}=0,05$; $\mathrm{q}=0,05 ; \mathrm{t}=1,96$ ve $\mathrm{d}=0,05) 341$ olarak hesaplanmıştır. Hasta anket formlarında gözlemlenen doldurulmamış ve eksik bölümler çıkarıldıktan sonra analizler toplam 350 birey üzerinden gerçekleştirilmiştir. Çalışmanın analiz kısmında SPSS ve LISREL paket programlarından yararlanılmıştır.

Bu amaçla Araştırma ve Yayın Etiğine uyularak, Helsinki Deklerasyonu Prensiplerine uygun ve 2019/4 etik kurul karariyla toplanan verilere, betimleyici istatistiksel analizlerin dışında açıklayıcı faktör analizi, doğrulayıcı faktör analizi ve yapısal eşitlik modellemesi uygulanarak bireylerin bilgiye ve korkuya dayalı tutum ve davranış boyutları belirlenerek ağız ve diş sağlığı konusundaki davranışları üzerinde etkili olan tutumları belirlenmiştir. Çalışmadan elde sonuçlarına göre, korkuya dayalı davranışları üzerinde korkuya dayalı tutumları en etkili faktör olarak belirlenirken, bilgiye dayalı davranışları üzerinde ise bilgiye dayalı tutumları en etkili faktör olarak belirlenmiştir. Elde edilen diğer bulgular ilgili çizelge ve şekillerde verilmiştir.

\section{İstatistiksel Analiz}

Derlenen verilerin analizinde betimleyici istatistiklerin dışında güvenirlilik analizi, Açıklayıcı Faktör Analizi (AFA), Doğrulayıcı Faktör Analizi (DFA) ve Yapısal Eşitlik Modellemesinden (YEM) yararlanılmıştır.

\section{BULGULAR}

Katılımcıların Bireylerin demografik özellikleri ve bilgiye dayalı tutum ve davranışları ile korkuya dayalı tutum ve davranışlarına ilişkin ortalama, standart sapma (s.s) değerleri Tablo 1'de sunulmuştur. Tablo 1 incelendiğinde, katılımcıların \%60,0'ının kadın ve \%40,9'unun erkek olduğu, $\% 25,1$ 'inin $18-25$ yaş, $\% 25,4$ 'ünün 26-33 yaş, \%24,0'ının 34-41 yaş, \%13,4'ünün 42-49 yaş ve \%12,0'ının 55 yaşının üzerinde olduğu, \%7,4'ünün ilkokul, \%6'sinın ortaokul, \%26,6'sınınlise, \%45,4'ünün üniversite, \%10,0'ının lisansüstü ve \%4,6'sının ise doktora mezunu olduğu görülmektedir.

Tablo1'den de görüleceği üzere, ağız ve diş sağlığı konusunda bilgiye dayalı tutum ve bilgiye dayalı davranış puan ortalaması cinsiyet bazında incelendiğinde, kadınların daha yüksek bir ortalama puana sahip oldukları görülmektedir. $\mathrm{Bu}$ bireyler korkuya dayalı tutum ve davranışları bakımından incelendiğinde ise, erkeklerin daha düşük ortalamaya sahip olduğu, dolayısıyla erkek bireylerin diş tedavisi konusunda daha elverişli olduğu söylenebilir. 
Tablo 1. Bireylerin demografik özellikleri ve bilgiye dayalı tutum ve davranışları ile korkuya dayalı tutum ve davranışlarına ilişkin ortalama (ort.), standart sapma (s.s) değerleri

\begin{tabular}{|c|c|c|c|c|c|c|c|c|c|c|}
\hline \multirow[b]{2}{*}{ CINSIYYET } & \multirow[b]{2}{*}{$\mathrm{n}$} & \multirow[b]{2}{*}{$\%$} & \multicolumn{2}{|c|}{ BD } & \multicolumn{2}{|c|}{ BT } & \multicolumn{2}{|c|}{ KD } & \multicolumn{2}{|c|}{ KT } \\
\hline & & & Ort. & S.S & Ort. & S.S & Ort. & S.S & Ort. & S.S \\
\hline Kadın & 210 & 60,0 & 3,75 & 0,86 & 4,16 & 0,69 & 2,49 & 0,93 & 2,76 & 1,09 \\
\hline Erkek & 140 & 40,0 & 3,40 & 0,91 & 3,89 & 0,84 & 2,38 & 0,88 & 2,69 & 1,09 \\
\hline \multicolumn{11}{|l|}{ YAŞ } \\
\hline $18-25$ & 88 & 25,1 & 3,70 & 0,9 & 4,07 & 0,75 & 2,36 & 0,91 & 2,71 & 1,07 \\
\hline $26-33$ & 89 & 25,4 & 3,66 & 0,86 & 4,10 & 0,70 & 2,34 & 0,83 & 2,64 & 1,12 \\
\hline $34-41$ & 84 & 24,0 & 3,53 & 0,86 & 4,00 & 0,78 & 2,43 & 0,95 & 2,75 & 1,13 \\
\hline $42-49$ & 47 & 13,4 & 3,66 & 0,84 & 4,19 & 0,53 & 2,74 & 0,96 & 2,96 & 1,00 \\
\hline $50+$ & 42 & 12,0 & 3,43 & 1,09 & 3,85 & 1,07 & 2,54 & 0,90 & 2,60 & 1,08 \\
\hline \multicolumn{11}{|l|}{$\begin{array}{l}\text { EĞİTİM } \\
\text { DURUMU }\end{array}$} \\
\hline İlkokul & 26 & 7,4 & 3,40 & 1,04 & 3,85 & 0,76 & 2,51 & 0,79 & 2,52 & 1,00 \\
\hline Ortaokul & 21 & 6,0 & 3,07 & 1,00 & 3,81 & 0,67 & 2,72 & 0,96 & 2,70 & 0,95 \\
\hline Lise & 93 & 26,6 & 3,64 & 0,92 & 3,88 & 0,75 & 2,58 & 0,84 & 2,89 & 1,07 \\
\hline Üniversite & 159 & 45,4 & 3,67 & 0,81 & 4,17 & 0,74 & 2,37 & 0,93 & 2,73 & 1,10 \\
\hline Y. Lisans & 35 & 10,0 & 3,66 & 0,89 & 4,15 & 0,90 & 2,38 & 0,96 & 2,57 & 1,17 \\
\hline Doktora & 16 & 4,6 & 3,57 & 1,03 & 4,26 & 0,68 & 2,07 & 0,95 & 2,31 & 1,16 \\
\hline
\end{tabular}

BD: Bilgiye Dayalı Davranış, BT: Bilgiye Dayalı Tutum, KD: Korkuya Dayalı Davranış, KT: Korkuya Dayalı Tutum

Yaş bazında incelendiğinde bilgiye dayalı tutum ve bilgiye dayalı davranış puan ortalamalarının 50 yaş üzeri bireylerde en düşük olduğu görülmektedir. Bu sonuca göre bireylerin yaşı arttıkça bilgi düzeylerinin azaldığ söylenebilir, diğer taraftan yaş bazında korkuya dayalı tutum ve korkuya dayalı davranış ortalamalarına bakıldığında en yüksek ortalamalar 42-49 yaş aralığında görülmektedir. $\mathrm{Bu}$ sonuca göre 42-49 yaş aralığındaki bireylerin ağız ve diş tedavisi konusunda en elverişsiz yaş grubu olduğu söylenebilir.

Son olarak ağız ve diş sağlığ 1 konusunda bilgiye dayalı tutum ve bilgiye dayalı davranış puan ortalaması eğitim durumu bazında incelendiğinde en düşük puan ortalaması ortaokul kategorisinde görülmektedir, bunun yanında bilgiye dayalı davranış puan ortalaması en yüksek üniversite kategorinde bilgiye dayalı tutum ortalaması ise en yüksek doktora kategorisinde görülmektedir. Korkuya dayalı tutum ve korkuya dayalı davranış incelendiğinde ise en düşük puan ortalaması doktora kategorisinde görülmektedir. $\mathrm{Bu}$ sonuçlara bakılarak eğitim düzeyi düştüğünde bireylerin bilgi seviyesi azalmakta eğitim düzeyi yükseldikçe bilgi seviyesi de onunla birlikte yükselmekte denilebilir. Korkuya dayalı tutum ve korkuya dayalı davranış sonuçlarına da bakıldığında ağız ve diş sağlığı üzerinde eğitim düzeyi arttıkça bilgi seviyesi artmakta, bilgi seviyesi attıkça korku seviyesinin düşmekte olduğu söylenebilir.

Tutum ve Davranışa ilişkin AFA'ya ait bulgular Tablo 2'de verilmiştir. AFA'da yer alan Tutum ve Davranışa ilişkin maddelerin geneli için güvenirlilik katsayısı olan Cronbach alfa değeri 0,806 olarak hesaplanmıştır ki bu değerler kullanılan ölçeğin güvenilir olduğunun bir göstergesidir.

Tablo 2 incelendiğinde kullanılan ölçekte daha fazla soru olmasına rağmen açıklayıcı faktör analizi uygulanırken teorik çerçevede Tutum ve Davranış olarak 4 faktörde toplanması beklenilen soruların daha fazla faktörde kendini göstermesi hem de Korkuya dayalı tutum, Bilgiye dayalı tutum, Korkuya dayalı davranış ve Bilgiye dayalı davranışa ait soruların oluşturduğu faktörün birbirleri içerisinde yer almasından dolayı (Varimax döndürmesi yapıldıktan sonra) Tutum iki faktör ile toplam 10 soru, Davranış da iki faktör ile toplam 14 soru ile açıklanabilmiştir. Korkuya dayalı davranışları 8 madde ile Bilgiye dayalı davranışları 6 madde ile Bilgiye dayalı tutumları 5 madde ile Korkuya dayalı tutum 5 madde ile açıklanabilmiştir. Açıklayıcı faktör analizi sonucunda bu dört faktör toplam varyansın \% 56,575'ini açıklamaktadır. Faktörler içerisindeki yükleri bakımından Korkuya dayalı tutum için 0,860'lı yük ile KT1 değişkeni, Korkuya dayalı davranış için 0,756 'lık yük ile KD1 değişkeni, Bilgiye dayalı davranış için 0,798'lik yük ile BD1 değişkeni, Bilgiye dayalı tutum değişkeni için ise 0,772'lik yük ile BT1 değişkenlerinin en etkili değişkenler olduğu görülmektedir. Her bir faktöre ait özdeğerler, varyans açıklama oranları ve Cronbach alfa değerleri de Tablo 2'den görülebilir.

Tutumun alt boyutlarının yer aldığ DFA analizi sonuçları Şekil 1'de verilmektedir.

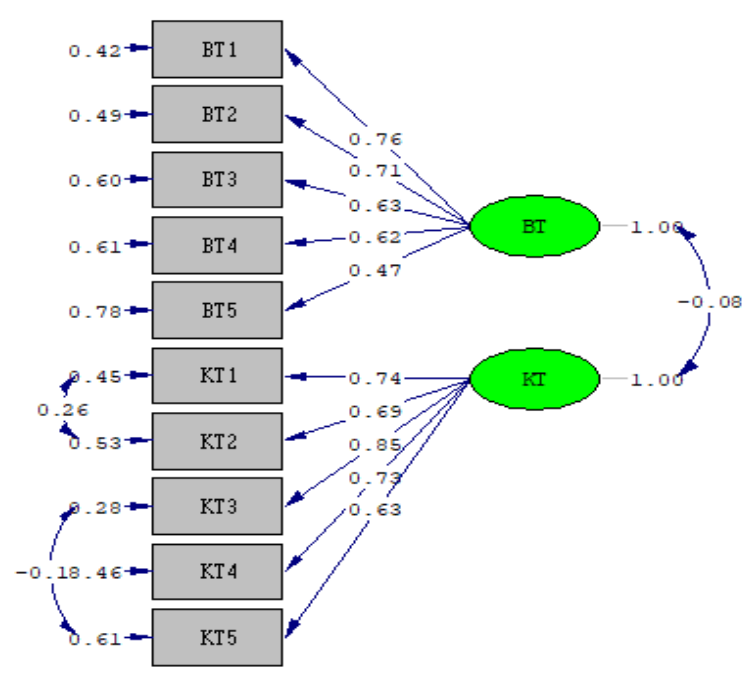

Chi-Square $=86.02, d f=32, \mathrm{P}$-value $=0.00000, \mathrm{RMSEA}=0.070$

Şekil 1.Tutuma ilişkin DFA analizi sonuçları 
Tablo 2.Tutum ve Davranış değişkenlerine ait AFA sonuçları ve Cronbach $\alpha$ değerleri.

\begin{tabular}{|c|c|c|c|c|}
\hline Faktörler/Maddeler & $\begin{array}{c}\text { Faktör } \\
\text { Yükü }\end{array}$ & Özdeğer & $\begin{array}{l}\text { Açıklanan } \\
\text { Varyans } \\
(\%)\end{array}$ & $\alpha$ \\
\hline KT Korkuya dayalı tutum & & & & \\
\hline KT1. Anestezik iğnenin görüntüsü beni endişelendirir. & 0,860 & \multirow{5}{*}{6,184} & \multirow{5}{*}{15,616} & \multirow{5}{*}{0,853} \\
\hline KT2. Anestezik iğnenin batma hissi beni korkutur. & 0,794 & & & \\
\hline $\begin{array}{l}\text { KT3. Diş hekiminin canımı yakacağı konusunda } \\
\text { endişelenirim. }\end{array}$ & 0,764 & & & \\
\hline $\begin{array}{l}\text { KT4. Diş hekimi randevusunu günler öncesinden düşünerek } \\
\text { sikıntı hissederim. }\end{array}$ & 0,743 & & & \\
\hline $\begin{array}{l}\text { KT5. Hekim koltuğundayken ölüm korkusu gibi kötü } \\
\text { düşünceler aklıma gelir. }\end{array}$ & 0,567 & & & \\
\hline \multicolumn{5}{|l|}{ KD Korkuya dayalı davranış } \\
\hline $\begin{array}{l}\text { KD1. Kullanılan aletlerin sesleri beni rahatsız ettiği için } \\
\text { müzik dinlerim. }\end{array}$ & 0,756 & \multirow{8}{*}{4,025} & \multirow{8}{*}{14,587} & \multirow{8}{*}{0,844} \\
\hline KD2. Korku ile dental objeleri yutabilirim. & 0,722 & & & \\
\hline $\begin{array}{l}\text { KD3. Diş tedavim sırasında canım acımasa bile strese bağlı } \\
\text { bayılabilir ya da kontrolümü kaybedebilirim. }\end{array}$ & 0,688 & & & \\
\hline $\begin{array}{l}\text { KD4. Kullanılan aletleri görmek beni korkuttuğu için } \\
\text { gözlerimi kapatırım. }\end{array}$ & 0,666 & & & \\
\hline KD5. İşlem sırasında ağzımda biriken su boğulma hissi verir. & 0,553 & & & \\
\hline $\begin{array}{l}\text { KD6. Diş hekiminin muayenehanesinde beklerken kendimi } \\
\text { gergin hissettiğim için başka şeylerle ilgilenirim. (tv izlemek, } \\
\text { dergi okumak vs. ) }\end{array}$ & 0,550 & & & \\
\hline $\begin{array}{l}\text { KD7. Diş hekiminin muayenehanesinde beklerken kalp } \\
\text { atışlarım artar, ellerim terler. }\end{array}$ & 0,528 & & & \\
\hline $\begin{array}{l}\text { KD8. İşlem sırasında stres sebebiyle tedavimi yarıda } \\
\text { bırakabilirim. }\end{array}$ & 0,445 & & & \\
\hline \multicolumn{5}{|l|}{ BD Bilgiye dayalı davranış } \\
\hline BD1. Dişlerimi düzenli şekilde günde 2 defa firçalarım. & 0,798 & \multirow{6}{*}{2,089} & \multirow{6}{*}{13,393} & \multirow{6}{*}{0,821} \\
\hline $\begin{array}{l}\text { BD2. Ağız hijyeni için sadece diş firçalamak yetmez bunun } \\
\text { yanında gargara da kullanırım. }\end{array}$ & 0,736 & & & \\
\hline $\begin{array}{l}\text { BD3. Ağız ve diş sağlığımın kontrolü için düzenli olarak } 6 \\
\text { ayda bir diş hekimine giderim. }\end{array}$ & 0,726 & & & \\
\hline $\begin{array}{l}\text { BD4. Ağız hijyeni için sadece diş fırçalamak yetmez bunun } \\
\text { yanında diş ipi de kullanırım. }\end{array}$ & 0,695 & & & \\
\hline BD5. Ağız ve diş sağlığıma gereken önemi veririm. & 0,677 & & & \\
\hline BD6. Diş fırçamı düzenli olarak 6 ayda bir değiştiririm. & 0,589 & & & \\
\hline \multicolumn{5}{|l|}{ BT Bilgiye dayalı tutum } \\
\hline $\begin{array}{l}\text { BT1. Ağız ve diş sağlığı genel vücut sağlığı ile etkileşim } \\
\text { içindedir. }\end{array}$ & 0,772 & \multirow{5}{*}{1,280} & \multirow{5}{*}{12,978} & \multirow{5}{*}{0,770} \\
\hline $\begin{array}{l}\text { BT2. Diş firçasının kişiye özel olması ağız ve diş sağlığı için } \\
\text { önemli bir etkendir. }\end{array}$ & 0,714 & & & \\
\hline $\begin{array}{l}\text { BT3. Ağız ve diş sağlığında genetik faktörlerin etkili } \\
\text { olduğunu düşünüyorum. }\end{array}$ & 0,700 & & & \\
\hline $\begin{array}{l}\text { BT4. Bireylerin ağız ve diş sağlığı durumuna göre farklı diş } \\
\text { macunu kullanması gerektiğini bilirim. }\end{array}$ & 0,648 & & & \\
\hline $\begin{array}{l}\text { BT5. Türk toplumunda ağız ve diş sağlığı problemlerinin } \\
\text { yaygın olduğunu düşünüyorum. }\end{array}$ & 0,629 & & & \\
\hline
\end{tabular}

Tutumun alt boyutları olan Korkuya dayalı tutum (KT), Bilgiye dayalı tutum (BT) için Şekil 1'de verilen doğrulayıcı faktör analizi sonuçları incelenmektedir. Buna göre bireylerin Bilgiye dayalı tutumları üzerinde en etkili değişkenin 0,76'lık katsayı yükü ile BT1 “Ağız ve diş sağlığı genel vücut sağlığ içindedir.”değişkeni olduğu görülmektedir. Bu değişkeni 0,71'lik yük ile BT2 "Diş firçasının kişiye özel olması ağız ve diş sağlığı için önemli bir etkendir.” değişkenin olduğu görülmektedir.

Bireylerin Korkuya dayalı tutumları üzerinde ise en etkili değişkenin 0,85'lik katsayı yükü ile KT3 'Diş hekiminin canımı yakacağı konusunda endișelenirim." değișkeni olduğu, bu değişkeni 0,74 'lik yükler ile KT1 “Anestezik iğnenin görüntüsü beni endişelendirir."

Çalışmanın uygulama kısmında kurulan DFA'ya ait uyum kriterlerinin yer aldığı Tablo 3 incelendiğinde Tutuma ilişkin DFA analizi için tüm kriterlerin şartları sağladığı, dolayısıyla modelin istatistiksel olarak anlamlı bir model olduğunu söylemek mümkündür.

Bu kriterler dişında $\chi^{2}(32)=86,02(p=0,000) ; \chi^{2} / s d=2,69<$ 3 değeri de model uygunluğunun belirlenmesinde kullanılan diğer bir istatistik olup, modelin istatistiki açıdan uygun olduğunun diğer bir göstergesidir. 
Tablo 3. Kurulan DFA ve YEM modelleri için uyum kriterlerine ait değerler.

\begin{tabular}{|c|c|c|c|c|c|c|}
\hline $\begin{array}{c}\text { Uyum } \\
\text { Kriterleri }\end{array}$ & Mükemmel Uyum & $\begin{array}{c}\text { Kabul Edilebilir } \\
\text { Uyum }\end{array}$ & T & D & T-KD & T-BD \\
\hline RMSEA & $0<$ RMSEA $<0,05$ & $0,05 \leq \mathrm{RMSEA} \leq 0,10$ & 0,070 & 0,067 & 0,072 & 0,072 \\
\hline NFI & $0,95 \leq \mathrm{NFI} \leq 1$ & $0,90<\mathrm{NFI} \leq 0,95$ & 0,95 & 0,94 & 0,94 & 0,92 \\
\hline NNFI & $0,97 \leq \mathrm{NNFI} \leq 1$ & $0,95 \leq \mathrm{NNFI} \leq 0,97$ & 0,95 & 0,95 & 0,95 & 0,94 \\
\hline CFI & $0,97 \leq \mathrm{CFI} \leq 1$ & $0,95 \leq \mathrm{CFI} \leq 0,97$ & 0,97 & 0,96 & 0,96 & 0,95 \\
\hline SRMR & $0 \leq \mathrm{SRMR}<0,05$ & $0,05 \leq \mathrm{SRMR} \leq 0,10$ & 0,070 & 0,060 & 0,078 & 0,069 \\
\hline GFI & $0,95 \leq \mathrm{GFI} \leq 1$ & $0,90 \leq \mathrm{GFI} \leq 0,95$ & 0,95 & 0,93 & 0,90 & 0,91 \\
\hline AGFI & $0,90 \leq \mathrm{AGFI} \leq 1$ & $0,85 \leq \mathrm{AGFI} \leq 0,90$ & 0,92 & 0,90 & 0,86 & 0,88 \\
\hline
\end{tabular}

T:Tutum, D: Davranış, KD: Korkuya Dayalı Davranış, BD: Bilgiye Dayalı Davranış, RMSEA: Root Mean Square Error of Approximation, NFI: Normed Fit Index, NNFI: Non-Normed Fit Index, CFI: Comparative Fit Index, SRMR: Standardized Root Mean Square Residual, GFI: Goodness of Fit Index, AGFI: Adjusted Goodness of Fit Index

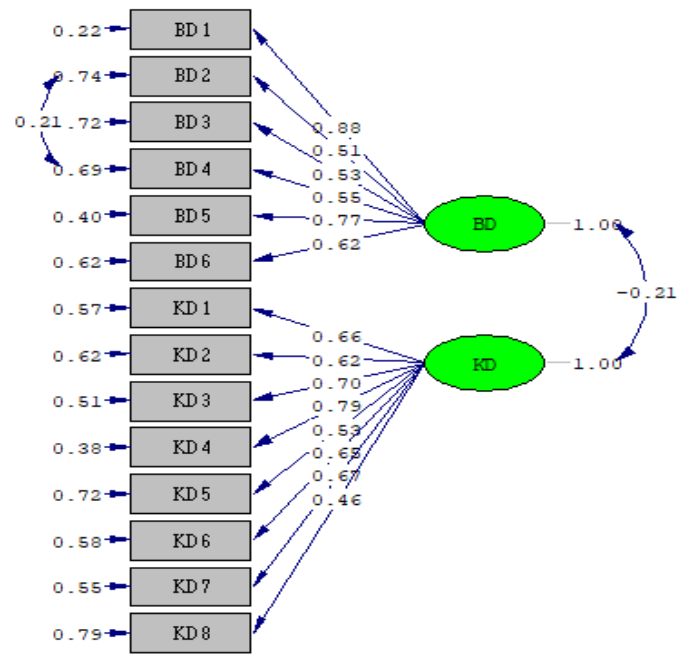

Şekil 2. Davranışa ilişkin DFA analizi sonuçları

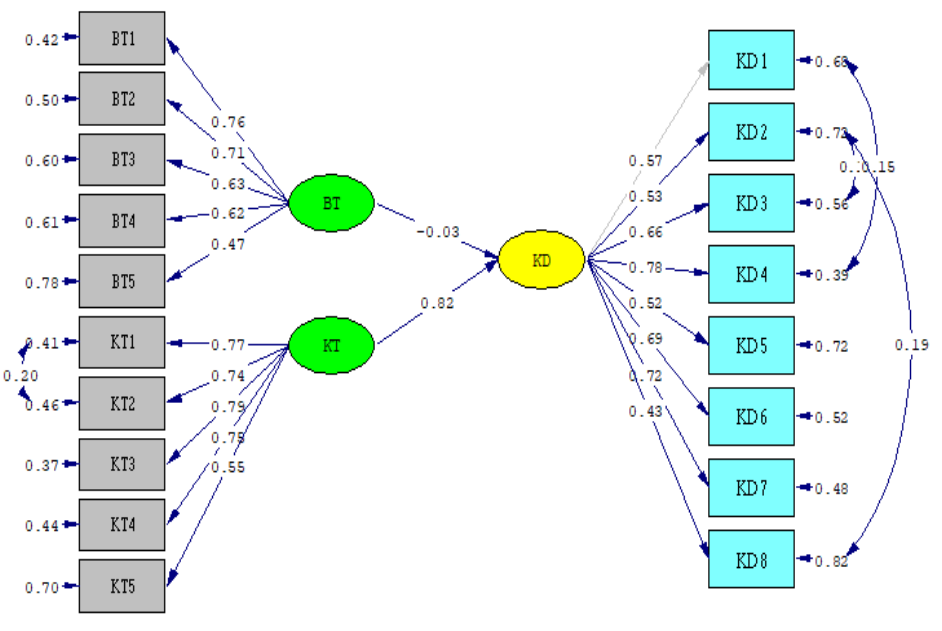

Chi-Square $=358.76, \mathrm{df}=128, \mathrm{p}$-value $=0.00000$, RMSEA $=0.072$

Şekil 3. Korkuya Dayalı Davranış ile Tutumun alt boyutlarına ilişkin YEM sonuçları

Tablo 4. Korkuya dayalı davranış ve Tutum'a ilişkin kurulan modele ait standartlaştırılmış parametre tahminleri, $t$ istatistikleri ve hipotezler

\begin{tabular}{|c|c|c|c|c|}
\hline Hipotezler & Yollar & $\begin{array}{c}\text { Standartlaştırılmış } \\
\text { Parametre Tahminleri }\end{array}$ & t istatistiği & Sonuç \\
\hline $\mathrm{H}_{1}$ & $(\mathrm{BT}) \rightarrow(\mathrm{KD})$ & $-0,03$ & $-0,63$ & Doğrulanmadı \\
\hline $\mathrm{H}_{2}$ & $(\mathrm{KT}) \rightarrow(\mathrm{KD})$ & 0,82 & 9,60 & Doğruland 1 \\
\hline
\end{tabular}

BT: Bilgiye Dayalı Tutum, KD: Korkuya Dayalı Davranış, KT: Korkuya Dayalı Tutum

Tablo 5. Bilgiye Dayalı Davranış ve Tutum'a ilişkin kurulan modele ait standartlaştırılmış parametre tahminleri, $t$ istatistikleri ve hipotezler

\begin{tabular}{|c|c|c|c|c|}
\hline Hipotezler & Yollar & $\begin{array}{c}\text { Standartlaştırılmış } \\
\text { Parametre Tahminleri }\end{array}$ & t istatistiği & Sonuç \\
\hline $\mathrm{H}_{3}$ & $(\mathrm{BT}) \rightarrow(\mathrm{BD})$ & 0,51 & 8,23 & Doğruland 1 \\
\hline $\mathrm{H}_{4}$ & $(\mathrm{KT}) \rightarrow(\mathrm{BD})$ & $-0,16$ & $-2,87$ & Doğruland 1 \\
\hline
\end{tabular}

BD: Bilgiye Dayalı Davranış, BT: Bilgiye Dayalı Tutum, KT: Korkuya Dayalı Tutum

Davranışın alt boyutlarının yer aldığı DFA analizi sonuçları Şekil 2'de verilmektedir. Davranışın alt boyutları olan Korkuya dayalı davranış (KD), Bilgiye dayalı davranış (BD) için Şekil 2'de verilen doğrulayıcı faktör analizi sonuçları incelenmektedir. Ele alınan bireylerin Bilgiye dayalı davranışları üzerinde en etkili değişkenin 0,88'lik katsayı yükü ile BD1 "Dişlerimi düzenli şekilde günde 2 defa firçalarım." değişkeni olduğu görülmektedir. Bu değişkeni 0,77'lik yük ile BD5 "Ağı ve diş sağlığıma gereken önemi veririm." Değişkeni takip etmektedir.

Bireylerin Korkuya dayalı davranışları üzerinde ise en etkili değişkenin 0,79'luk katsayı yükü ile KD4 "Kullanılan aletleri görmek beni korkuttuğu için 
gözlerimi kapatırım.” değişkeni olduğu, bu değişkeni 0,70'lik yükler ile KD3 "Diş tedavim sırasında canım acımasa bile strese bağlı bayılabilir ya da kontrolümü kaybedebilirim " değişkenlerinin olduğu görülmektedir. Çalışmanın uygulama kısmında kurulan DFA'ya ait uyum kriterlerinin yer aldığı Tablo 3 incelendiğinde Davranışa ilişkin DFA analizi için tüm kriterlerin şartları sağladığı, dolayısıyla modelin istatistiksel olarak anlamlı bir model olduğunu söylemek mümkündür.

$\mathrm{Bu} \quad$ kriterler dişında $\chi^{2}(75)=191,77 \quad(\mathrm{p}<0,001)$; $\chi^{2} / \mathrm{sd}=2,56<3$ değeri de model uygunluğunun belirlenmesinde kullanılan diğer bir istatistik olup, modelin istatistiki açıdan uygun olduğunun diğer bir göstergesidir.

Korkuya dayalı davranış ile Tutum arasındaki ilişkinin belirlenmesi için kurulan Yapısal eşitlik modellemesine ait sonuçlar Şekil 3 ve Tablo 3 'te verilmektedir. Korkuya dayalı tutumun ya da Bilgiye dayalı tutumun artması ile bireylerin Korkuya dayalı davranışlarının da artacağı düşüncesi ile bu gizil değişkenler için oluşturulan alternatif araştırma hipotezleri aşağıdaki gibi oluşturulmuştur.

- $\mathrm{H}_{1}$ :Bireylerin korkuya dayalı tutumları arttıkça korkuya dayalı davranışlarıda artar.

- $\mathrm{H}_{2}$ :Bireylerin bilgiye dayalı tutumları attıkça korkuya dayalı davranışları azalır.

Şekil 3'te yer alan yapısal eşitlik modellemesinde görüleceği üzere kurulan modelin uygunluğunu iyileştirmek (kabul edilebilir bir uyumdan mükemmel bir uyum sınırları içerisine çekebilmek) ya da uygun olmayan bir modeli uygun (yollara ait $\mathrm{t}$ istatistikleri açısından da anlamlı) bir hale getirebilmek için LISREL Programı kullanılmıştır. Bu programda yer alan çıktıda belirtilen ve teorik olarak da anlamlı olan önerilere bağlı olarak bazı modifikasyonlar (maddelere ait hata kovaryansları serbest bırakılmıştır) yapılmıştır. Benzer olarak Şekil 4'te verilen ve Tutum ile Bilgiye dayalı davranışın alt boyutları arasındaki ilişkinin modellendiği analiz için de birtakım modifikasyonlar yapılmıştır.

Şekil 3 incelendiğinde, DFA'ya benzer olarak bireylerin Bilgiye dayalı tutumları üzerinde BT1 "Ağız ve diş sağlığ1 genel vücut sağlığ1 ile etkileşim içindedir." değişkeninin etkili değişken olduğu görülmektedir. Korkuya dayalı tutumları üzerinde KT3 "Diş hekiminin canımı yakacağı konusunda endişelenirim.” değişkeninin en etkili değişken, Korkuya dayalı davranış üzerinde ise KD4 "Kullanılan aletleri görmek beni korkuttuğu için gözlerimi kapatırım.” değişkeninin en etkili değişken olduğu görülmektedir.

Bilgiye dayalı tutumda meydana gelen bir birimlik artışın bireylerin korkuya dayalı davranışında 0,03 birimlik bir azalmaya sebep olurken, bireylerin korkuya dayalı tutumda ki 1 birimlik artışın korkuya dayalı davranışta 0,82 birimlik bir artışa sebep olacağı söylenebilir.

Şekil 3'te kurulan YEM'e ait hipotez testlerinin sınanmasında kullanılan t istatistiği değerleri ve sonuçları Tablo 4'te verilmiştir.

Tablo 4 incelendiğinde $\mathrm{H} 1$ hipotezinde yer alan iddianın doğrulanmazken, $\mathrm{H}_{2}$ hipotezinde yer alan iddianın istatistiksel olarak doğrulandığ görülmektedir.
Bilgiye dayalı davranış ile Tutum arasındaki ilişkinin belirlenmesi için kurulan yapısal eşitlik modellemesine ait sonuçlar Şekil 4 ve Tablo 3 'te verilmektedir. Bilgiye dayalı tutum ile korkuya dayalı tutum da meydana gelecek bir artışı bireylerin bilgiye dayalı davranışlarında da bir artışa sebep olacağı düşüncesi ile bu gizil değişkenler için oluşturulan alternatif araştırma hipotezleri aşağıdaki gibi oluşturulmuştur.

- $\mathrm{H}_{3}$ :Bireylerin bilgiye dayalı tutumları arttıkça bilgiye dayalı davranışları da artar.

- $\mathrm{H}_{4}$ :Bireylerin korkuya dayalı tutumları arttıkça bilgiye dayalı davranışları da azalır.

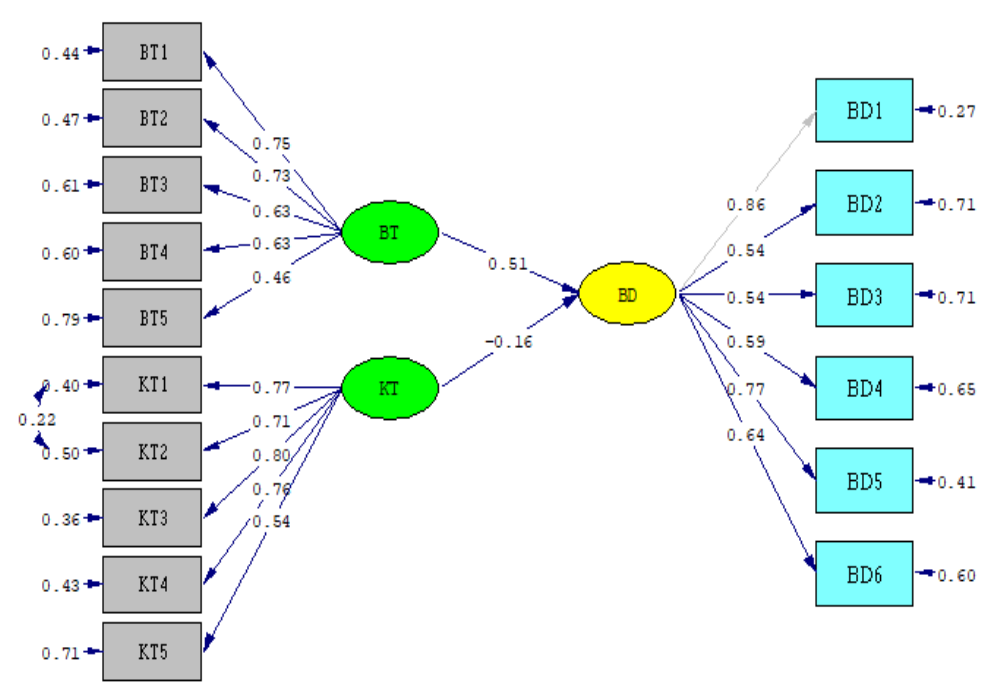

Chi-Square $=280.17, \mathrm{df}=100, \mathrm{P}-\mathrm{value}=0.00000, \mathrm{RMSEA}=0.072$

Şekil 4.Bilgiye Dayalı Davranış ile Tutumun alt boyutlarına ilişkin YEM sonuçları.

Şekil 4 incelendiğinde, DFA sonuçlarına ve korkuya dayalı davranışa ait YEM'e benzer olarak bireylerin Bilgiye dayalı tutumları üzerinde BT1 "Ağız ve diş sağlığ1 genel vücut sağlı̆̆1 ile etkileşim içindedir." değişkeninin etkili değişken olduğu görülmektedir. Korkuya dayalı tutumları üzerinde ise KT3 "Diş hekiminin canımı yakacağı konusunda endişelenirim." değişkeninin yine en etkili değişken, Bilgiye dayalı davranış üzerinde BD1 "Dişlerimi düzenli şekilde günde 2 defa firçalarım." değişkeninin en etkili değişken olduğu görülmektedir.

Bilgiye dayalı tutumda bir birimlik artışın bireylerin bilgiye dayalı davranışında 0,51 birimlik bir artışa sebep olurken, bireylerin korkuya dayalı tutumdaki 1 birimlik artışın bilgiye dayalı davranışta 0,16 birimlik bir azalmaya sebep olacağı söylenebilir.

Şekil 4'te kurulan YEM'e ait hipotez testlerinin sınanmasında kullanılan t istatistiği değerleri ve sonuçları Tablo 5'te verilmiştir. Tablo 5 incelendiğinde $\mathrm{H}_{3}$ ve $\mathrm{H}_{4}$ hipotezlerinde yer alan iki iddianın da istatistiksel olarak doğrulandığı görülmektedir. 


\section{TARTIŞMA VE SONUÇ}

Verilerin analizinden yararlanılan ölçek, ortalama ve standart sapmalarının kategorik değişkenler bazındaki değerlerine ait tanımlayıcı istatistiksel analizler incelendiğinde, bilgiye ve korkuya dayalı tutum ve davranışları bakımından genellikle kadınların, üniversite mezunu olan bireylerin ve yaş kategorisi bakımından da 42-49 yaş gurubundaki bireylerin diğer bireylere göre daha yüksek bilgiye sahip ve buna paralel ve davranış sergiledikleri söylenebilir.

Elde edilen bulgular açıklayıcı faktör analizi sonuçları bakımından incelendiğinde Bireylerin korkuya dayalı tutumları üzerinde, en çok anestezik iğnenin görüntüsünün endişelendirdiği, Korkuya dayalı davranışları üzerinde en çok kullanılan aletlerin seslerinin rahatsız ettiği için müzik dinlemeleri, bilgiye dayalı davranışları üzerinde en çok dişlerini düzenli olarak günde 2 defa firçalamaları ve bilgiye dayalı tutumları üzerinde ise en çok ağız ve diş sağlığının genel vücut sağlığı ile etkileşim içinde olduğu ortaya çıkmıştır.

Yapısal eşitlik modellemesi sonuçları incelendiğinde, bireylerin bilgiye dayalı tutumlarındaki olumlu gelişmelerin bilgiye dayalı davranışlarında da olumlu gelişmeye sebep olduğu, korkuya dayalı tutumlarındaki artışların bilgiye dayalı davranışlarında olumsuz gelişmeye sebep olduğu istatistiksel olarak söylenebilir.

Bireylerin korkuya dayalı tutumlarındaki artışın korkuya dayalı davranışları üzerinde de bir artışa sebep olduğu bunun yanında bilgiye dayalı tutumlarındaki bir artışın ise, korkuya dayalı davranışları üzerinde bir azalışa sebep olduğu istatistiksel olarak söylenebilir.

Yazarların Katkıları: Fikir/Kavram: F.A., S.S.; Tasarım: F.A., S.S.; Veri Toplama ve/veya İşleme: F.A., S.S.; Analiz ve/veya Yorum: F.A., S.S.; Literatür Taraması: F.A., S.S.; Makale Yazımı: F.A., S.S.; Eleştirel İnceleme: F.A., S.S.

\section{KAYNAKLAR}

1. Büyük DŞ, Çetinkaya A, Özmen D, Taylan A, Uyar, F. 11-12 yaş grubu çocukların ağız ve diş sağlığı konusundaki bilgi ve davranışlarının değerlendirilmesi. Dokuz Eylül Üniversitesi Hemşirelik Fakültesi Elektronik Dergisi. 2018; 11(2): 78-86.

2. Aydemir H, Ceylan KG. Orta karadeniz bölgesinde yaşayan bireylerin ağız-diş sağlığı düzeyi. Atatürk Üniversitesi Diş Hekimliği Fakültesi Dergisi. 1999; 9(1): 96-9.

3. Satcher D. Oral health in America: a report of the surgeon general. Rockville, MD: National Institute of Dental and Craniofacial Research, National Institutes of Health; 2000.

4. Beaglehole R. The oral health atlas: mapping a neglected global health issue. Geneva: FDI World Dental Federation; 2009.

5. Kaya S. Ağız ve diş sağlığı hastalarında yaşam kalitesinin incelenmesi [Yüksek Lisans Tezi]. Ankara: Hacettepe ÜniversitesiSosyal Bilimler Enstitüsü; 2014.

6. Genderson MW, Sischo L, Markowitz K, Fine D, Broder HL. An overview of children's oral healthrelated quality of life assessment: from scale development to measuring outcomes. Caries Research. 2013; 47(1): 13-21.

7. Kumar P, Kumar P, Dixit A, Grupta V, Singh H, Sargaşyan V. Cross sectional evaluation of awareness of prevention of dental caries among general paediatricians in Ghaziabad district, India. Annals of Medical and Health Sciences Research. 2014; 4(3): 302-6.

8. Kılınç G, Günay T. Dokuz Eylül Üniversitesi tıp fakültesi son sınıf öğrencilerinin ağız diş sağlığ konusunda bilgi düzeyleri. Dokuz Eylül Üniversitesi Tıp Fakültesi Dergisi. 2010; 24(3): 131-7.

9. Öztunç H, Haytaç, MC, Özmeriç N, Uzel İ. Adana ilinde 6-11 yaş grubu çocukların ağız-diş sağlığ durumlarının değerlendirilmesi. Gazi Üniversitesi Diş Hekimliği Fakültesi Dergisi. 2000; 17(2): 1-6.

10. Källestål C, Matsson L, Holm AK. Periodontal conditions in a group of Swedish adolescents (I). A descriptive epidemiologic study. Journal of Clinical Periodontology. 1990; 17(9): 601-8.

11. Özmeriç N, Göfteci B, Kurtiş B, Bal B. Arayüz bakımı ve periodontal sağlık. Gazi Üniversitesi Diş Hekimliği Fakültesi Dergisi. 1994; 11(2): 33-8.

12. Tulunoğlu Ö, Bodur H, Akal N. Aile eğitim düzeyinin okul öncesi çocuklardaki ağız diş sağlığı uygulamaları üzerine etkisinin değerlendirilmesi. Gazi Üniversitesi Diş Hekimliği Fakültesi Dergisi. 1999; 16(2): 27-32.

13. Pattanaporn K, Navia JM. The relationship of dental calculus to caries, gingivitis, and selected salivary factors in 11-to 13-year-old children in Chiang Mai, Thailand. Journal of Periodontology. 1998; 69(9): 955-61.

14. Gibson S, Williams S. Dental caries in pre-school children: associations with social class, toothbrushing habit and consumption of sugars and sugarcontaining foods. Caries Research. 1999; 33(2): 10113.

15. Çalışkan D, Yaşar F, Tunçbilek A. AÜ TF 9-10 sömestr öğrencilerinin ağız ve diş sağlığ 1 konusunda bilgi düzeyleri. Ankara Üniversitesi Tıp Fakültesi Mecmuas1. 2002; 55(2): 137-42.

16. Rabiei S, Mohebbi SZ, Patja K, Virtanen JI. Physicians' knowledge of and adherence to improving oral health. BMC Public Health. 2012; 12(1): 855.

17. Adeghe HA, Ehigiator O, Azodo CC, Ehizele AO. Nigerian clinical level medical students' knowledge of dental specialty. Annals of Medical and Health Sciences Research. 2012; 2(2): 157-60.

18. Koşan Z, Akgül N, Bedir B, Çalıkoğlu EO, Yılmaz S, Derelioğlu SD. Tıp ve diş hekimliği fakültelerinde ağız - diş sağlığı eğitimi yeterli mi? Öğrencilerin bilgi düzeylerinin karşılaştırılması. Turk J Public Health. 2017; 15(3): 201-12.

19. Vishwanathaiah S. Knowledge, attitudes, and oral health practices of school children in davangere. International Journal of Clinical Pediatric Dentistry. 2016; 9(2): 172-6.

20. TDB [İnternet] Türk Diş Hekimleri Birliği, 2015. [Erişim tarihi: 15.08.2016] Erişim adresi: http://www.tdb.org.tr/tdb/v2/basin_icerik.php?yer_id $=5 \& i d=64$.

21. Tekçiçek M. Okul sağlığı programlarında ağız diş sağlığının önemi ve kapsamı. Halk Sağlığı Günleri III. 
Ulusal Okul Sağlığı Sempozyumu; 4-9 Eylül 2014; Ankara.

22. WHO. Oral health surveys: basic methods. 5. ed. 2013. France: World Health Organization; 2013.

23. Namal N, Ertem-Vehid H, Vehid S, Can G. Alt1-on iki yaş grubu çocukların diş sağlığını etkileyen anneye ait faktörlerin araştırılması. Çocuk Dergisi. 2009; 9(3): 123-6.

24. Pekcan H. Okul sağlığı içinde halk sağlığı temel bilgiler 1. 3. Bask1. Ankara: Hacettepe Üniversitesi Yayınları; 2015.

25. Bhardwaj VK, Sharma KR, Luthra RP, Jhingta P, Sharma D, Justa A. Impact of school-based oral health education program on oral health of 12 and 15 years old school children. Journal of Education and Health Promotion. 2013; 2: 33-45.

26. Amschler DH. A hidden epidemic: dental disparities among children. (Commentaries). Journal of School Health. 2003; 73(1): 38-41.

27. Jackson SL, Vann WF, Kotch JB, Pahel BT, Lee JY. Impact of poor oral health on children's school attendance and performance. American Journal of Public Health. 2011; 101(10): 1900-6.

28. TÜİK[İnternet] İstatistiklerle Çocuk. 2015 [Erişim tarihi: 20.04.2019] Erişim adresi: http://www.tuik.gov.tr/Kitap.do?metod=KitapDetay\& KT_ID=11\&KITAP_ID=269.

29. Haque SE, Rahman M, Itsuko K, Mutahara M, Kayako S, TsutsumiIslam MJ, et al. Effect of a school-based oral health education in preventing untreated dental caries and increasing knowledge, attitude, and practices among adolescents in Bangladesh. BioMed Central Oral Health. 2016; 44(16): 1-10.

30. Güler Ç, Eltas A, Güneş D, Görgen VA, Ersöz M. Malatya ilindeki 7-14 yaş arası çocukların ağız-diş sağlığının değerlendirilmesi. İnönü Üniversitesi Sağlık Bilimleri Dergisi. 2012; 2: 19-24.

31. Boorin MR. Anxiety. Its manifestation and role in the dentalpatient. Dental clinics of North America.1995; 39(3): 523-39.

32. Köroğlu DA, Durkan R. Diş hekimliği uygulamalarında karşılaşılan dental anksiyete sendromunun etiyolojisinin ve tedavi yöntemlerinin değerlendirilmesi. Atatürk Üniversitesi Diş Hekimliği Fakültesi Dergisi. 2010; 3: 205-12

33. AyerJr W, Domoto PK, Gale EN, JoyJr ED, Melamed BG. Overcoming dental fear: strategies for its prevention and management. Journal of the American Dental Association1939; 107(1): 18-27.

34. Abrahamsson KH, Berggren U, Carlsson SG. Psychosocial aspects of dental and general fears in dental phobic patients. Acta Odontol Scand. 2000; 58: 37-43.

35. Ünlüyol AY, Kocabalkan E. Diş tedavisi öncesi endişenin hastanın tedaviye bakış açısına etkisi. Gazi Üniversitesi Diş Hekimliği Fakültesi Dergisi. 2010; 27(3): 167-74.

36. Ay ZY, Erdek Y, Öztürk M, Kılınç G, Bozkurt Y, Yılmaz R. Süleyman Demirel Üniversitesi diş hekimliği fakültesine başvuran hastalarda dental korku düzeyinin incelenmesi. Cumhuriyet
Üniversitesi Diş Hekimliği Fakültesi Dergisi. 2005; 8(1): 12-8.

37. Tezel A, Yaman S. Erzurum ili ilkokul 4. ve 5. sınıf çocuklarının ağız ve diş sağlığı konusundaki bilgi tutum ve davranış düzeyinin araştırılması. Anadolu Hemşirelik ve Sağlık Bilimleri Dergisi. 2010; 1(1): 36-45.

38. Pekiner N. İstanbul'un sosyo-ekonomik yönden farklı iki ilköğretim okulunda uygulanan ağız ve diş sağlığı eğitiminin sonuçlarının karşılaştırılmalı olarak değerlendirilmesi [Doktora Tezi]. İstanbul: M.Ü. Sağlık Bilimleri Enstitüsü; 1999.

39. Yüksel R. Amasya İlindeki sınıf öğretmenlerinin ağız ve diş sağlığı konusundaki bilgi ve davranışları [Yüksek Lisans Tezi]. Ankara: Hacettepe Üniversitesi Eğitim Bilimleri Enstitüsü; 2018.

40. Schermelleh-Engel K, Moosbrugger $H$, Müller $H$. Evaluating the fit of structural equation models: tests of significance and descriptive goodness-of-fit measures. Methods of Psychological Research Online. 2003; 8(2): 23-74. 